\title{
Celulite juvenil canina - relato de casos
}

\section{Juvenile cellulitis in a puppy - case reports}

\author{
Carlos Eduardo Fonseca-Alves ${ }^{1 *}$; Aline Gonçalves Correa ${ }^{2}$; \\ Hérika Xavier da Costa ${ }^{3}$; Fabiana Elias ${ }^{4}$; Helvécio Leal Santos Junior ${ }^{5}$; \\ Sabrina dos Santos Costa ${ }^{5}$ Sabryna Gouveia Calazans ${ }^{6}$
}

\section{Resumo}

A celulite juvenil ou linfadenite granulomatosa estéril juvenil, é um distúrbio raro que acomete filhotes com idade entre três semanas a seis meses. Os sinais clínicos incluem alopecia, edema, pápulas, pústulas e crostas especialmente em pálpebras. O diagnóstico definitivo requer exames citológico e histopatológico e a terapia precoce e agressiva é preconizada, pois as cicatrizes após recuperação podem ser graves. O tratamento de escolha consiste no uso de altas doses dos glicocorticoides, como prednisona. Foram atendidos no Hospital Veterinário, três animais da espécie canina, apresentando sinais clínicos variados. Foram realizados hemograma, exame citológico das lesões de pele e dos linfonodos submandibulares. O tratamento foi instituído, utilizando-se cefalexina na dose de $22 \mathrm{mg} / \mathrm{kg}$, duas vezes ao dia, até controle de infecção bacteriana secundária e prednisona na dose de $2 \mathrm{mg} / \mathrm{kg}$, uma vez ao dia, até regressão dos sinais clínicos. Após termino do tratamento obteve-se cura completa dos animais. O objetivo deste trabalho é relatar o caso de três animais da espécie canina, apresentando sinais clínicos variados de celulite juvenil.

Palavras-chave: Celulite, canino, pústula

\begin{abstract}
Juvenile cellulitis or juvenile sterile granulomatous lymphadenitis is a rare disorder that affects puppies between three weeks to six months years old. Clinical signs include alopecia, edema, papules, pustules and crusts especially on eyelids. Definitive diagnosis requires cytological and histological evaluation and early and aggressive therapy is recommended, once scars after recovery can be severe. The choice treatment is the high dose of corticosteroids use such as prednisone. Three animals of canine species were attended at the Veterinary Hospital Clinical Small Animal Service presenting different clinical signs. Hemogram, skin lesions and submandibular lymph nodes cytological examination was collected and analyzed. The treatment was instituted, using cephalexin $(22 \mathrm{mg} / \mathrm{kg}$, twice daily) up to control of secondary bacterial infection, and prednisone $(2 \mathrm{mg} / \mathrm{kg}$, once a day) until clinical resolution. Complete cure was obtained at the end of treatment. The aim of this work is to report three clinical cases of juvenile cellulitis in dogs.
\end{abstract}

Key words: Cellulitis, canine, pustule

\footnotetext{
${ }^{1}$ Pós-Graduando, Programa de Pós-Graduação em Medicina Veterinária, Faculdade de Medicina Veterinária e Zootecnia, Universidade Estadual Paulista "Julio de Mesquita Filho", UNESP, Botucatu, SP. E-mail: carloseduardofa@hotmail.com

${ }^{2}$ Residente de Clínica Médica d Pequenos Animais, União Pioneira de Integração Social, Brasília, DF. E-mail: linelok@hotmail.com

${ }^{3}$ Pós-Graduanda, Programa de Pós-Graduação em Ciência Animal, Universidade Federal de Goiás, UFG, Goiânia, GO. E-mail: herikax@hotmail.com

${ }^{4}$ Prof ${ }^{a}$ Adjunto, Universidade Federal da Fronteira Sul, UFFS, Realiza, PR. E-mail: elias.fabiana@gmail.com

${ }^{5}$ Profs. União Pioneira de Integração Social, UPIS, Brasília, DF. E-mail: helvecio17@hotmail.com; bina1304@hotmail.com

${ }^{6}$ Prof ${ }^{a}$ Adjunto, Universidade de Franca, UNIFRAN, Franca, SP. E-mail: sgcalazans@gmail.com

* Autor para correspondência
} 


\section{Introdução}

A celulite juvenil é uma doença vesículopustular rara que acomete filhotes com idade entre três semanas a seis meses (SHIBATA; NAGATA, 2004). Não há predisposição sexual, no entanto a racial é evidente. Os cães das raças Teckel, Golden Retriever, Labrador Retriever, Gordon Setter, Beagle e Pointer são as mais acometidas (HUTCHINGS, 2003). Sua etiologia é incerta, estando relacionada à reação de hipersensibilidade e/ou doença viral (CARLOTTI, 2003). A herdabilidade é apoiada por um aumento da ocorrência em certas raças e pelo histórico familiar da doença (DAVIDSON, 2006). Malik et al. (1995) acreditam que exista associação entre o uso de vacinas e o surgimento da afecção, uma vez que observaram o desenvolvimento da doença após a administração de vacina polivalente em 4 cães.

As lesões cutâneas observadas nessa enfermidade incluem alopecia, edema, pápulas, pústulas, crostas e cicatrizes especialmente em pálpebras, lábios e região mentoniana (SCOTT; MILLER, 2007; NEUBER et al., 2004). Ocasionalmente as lesões cutâneas podem aparecer em extremidade de membros, abdome, tórax, vulva, prepúcio e ânus (JEFFERS; DUCLOS; GOLDSHMIDT, 1995; MEDLEAU; HNILICA, 2006). Os sinais clínicos observados podem acompanhar otite bilateral purulenta não pruriginosa, linfonodomegalia submandibular e em alguns casos abscedação dos linfonodos (SCOTT; MILLER, 2007; MEDLEAU; HNILICA, 2006).

O diagnóstico baseia-se nos exames citológico e histopatológico das lesões. A terapia precoce e agressiva é preconizada, pois as cicatrizes após recuperação podem ser graves. $\mathrm{O}$ tratamento de escolha consiste no uso de altas doses dos glicocorticoides, como prednisona $(2 \mathrm{mg} / \mathrm{Kg}$, SID) (MALIK et al., 1995). Geralmente, a avaliação citológica e a cultura bacteriana das lesões não revelam bactérias (PASA; VOYVODA, 2003). Porém, caso haja evidência citológica ou clínica de infecção secundária, o uso de antibióticos, a exemplo da cefalexina, cefadroxil e amoxicilina com clavulanato de potássio, deve ser associado ao tratamento com corticosteróides (SCOTT; MILLER, 2007). O tratamento tópico com acetato de alumínio ou sulfato de magnésio é útil, porém muito dolorosos e, portanto, pouco utilizado (SCOTT; MILLER, 2007).

O objetivo do presente trabalho é descrever os aspectos clínicos, epidemiológicos, citológicos, histopatológicos e terapêuticos de três casos de celulite juvenil em cães.

\section{Relato dos Casos}

Foram atendidos no Hospital Veterinário, três animais da espécie canina, apresentando sinais clínicos variados. O cão considerado número 1 era da raça Golden Retriver, com 60 dias de idade, fêmea e apresentava claudicação em membro torácico esquerdo, otite bilateral, edema, hiperemia e fissuras nos lábios, blefarite bilateral, aumento dos linfonodos submandibulares e lesões pustulares em região perivulvar. $\mathrm{O}$ cão número 2 era da raça Pointer Inglês, 90 dias de idade, macho e apresentava claudicação em membro pélvico direito, otite bilateral, edema, hiperemia e fissuras nos lábios, aumento dos linfonodos submandibulares e crostas na região periocular. $\mathrm{O}$ cão número 3 era da raça Pit Bull, com 60 dias de idade, fêmea e apresentava otite bilateral, edema, hiperemia e fissuras nos lábios, aumento dos linfonodos submandibulares, anorexia e hipertermia.

Foram realizados hemograma, exame citológico das lesões de pele e dos linfonodos submandibulares. Foram coletadas amostras de pele por biópsia incisional para avaliação histopatológica e cultivo bacteriano. Os animais foram submetidos ao mesmo protocolo terapêutico, utilizando-se cefalexina a 22 $\mathrm{mg} / \mathrm{kg}$, duas vezes ao dia, até controle de infecção bacteriana secundária, o que ocorreu após 21 dias de tratamento antimicroniano. Além disso, foi prescrito prednisona na dose de $2 \mathrm{mg} / \mathrm{kg}$, uma vez ao dia, até 
regressão dos sinais clínicos. Para retirada gradual do corticóide, a dose foi reduzida para $1 \mathrm{mg} / \mathrm{kg}$, duas vezes ao dia, por sete dias. Após este período, a dose foi reduzida para $0,5 \mathrm{mg} / \mathrm{kg}$, duas vezes ao dia, por sete dia. Finalizando, o tratamento prescrito foi prednisona $0,5 \mathrm{mg} / \mathrm{kg}$ uma vez ao dia por sete dias.

\section{Discussão}

Segundo Davidson (2006), a celulite juvenil é uma afecção pouco frequente, de caráter granulomatoso e pustular que acomete cães filhotes. No presente relato, os cães pertenciam respectivamente as seguintes raças: Golden Retriver, Pointer Inglês e Pit Bull. Medleau e Hnilica (2003) destacam a predisposição da raça Golden Retriever, Dachshund e Pointer. Os animais do presente relato apresentaram média de idade de 70 dias, situação que está de acordo com o descrito por Shibata e Nagata (2004), que afirmam que a celulite juvenil é uma doença vesículo-pustular que acomete filhotes entre 3 a 16 semanas de idade.

No presente relato os três animais haviam recebido a primeira dose da vacina óctupla, apresentando sinais clínicos com respectivamente
12, 17 e 21 dias após vacinação, o que fortalece a hipótese descrita por Malik et al. (1995). Estes pesquisadores relatam a possibilidade de haver relação desta enfermidade com a administração de vacinas, visto que, em um estudo, quatro de 15 cães observados desenvolveram a doença em menos de uma semana após administração da primeira dose da vacina polivalente, e em três animais havia sido realizado o plano vacinal completo.

O quadro clínico iniciou com claudicação (2/3), evoluindo para otite bilateral (1/3), edema de face $(3 / 3)$ (Figura 1), blefarite bilateral (3/3), lesões pustulares ao redor da vulva (1/3) e aumento de linfonodos submandibulares (3/3). O quadro foi compatível com os achados descritos por Medleau e Hnilica (2003). Um dos cães apresentou sinais sistêmicos da doença, apresentando anorexia e pirexia, corroborando com as descrições de Malik et al. (1995), que relatou a presença destes achados; além de dor nas articulações (artrite estéril supurativa) em até $25 \%$ dos casos. Os filhotes ocasionalmente têm paniculite piogranulomatosa estéril com firmes nódulos subcutâneos flutuantes que podem ser dolorosos e fistulares, estes nódulos ocorrem principalmente no tronco ou nas áreas prepucial ou perianal.

Figura 1. Alopecia, pápulas, pústulas e crostas especialmente nos lábios e pálpebras em filhote da raça PitBull (A) e Golden Retriver (B).

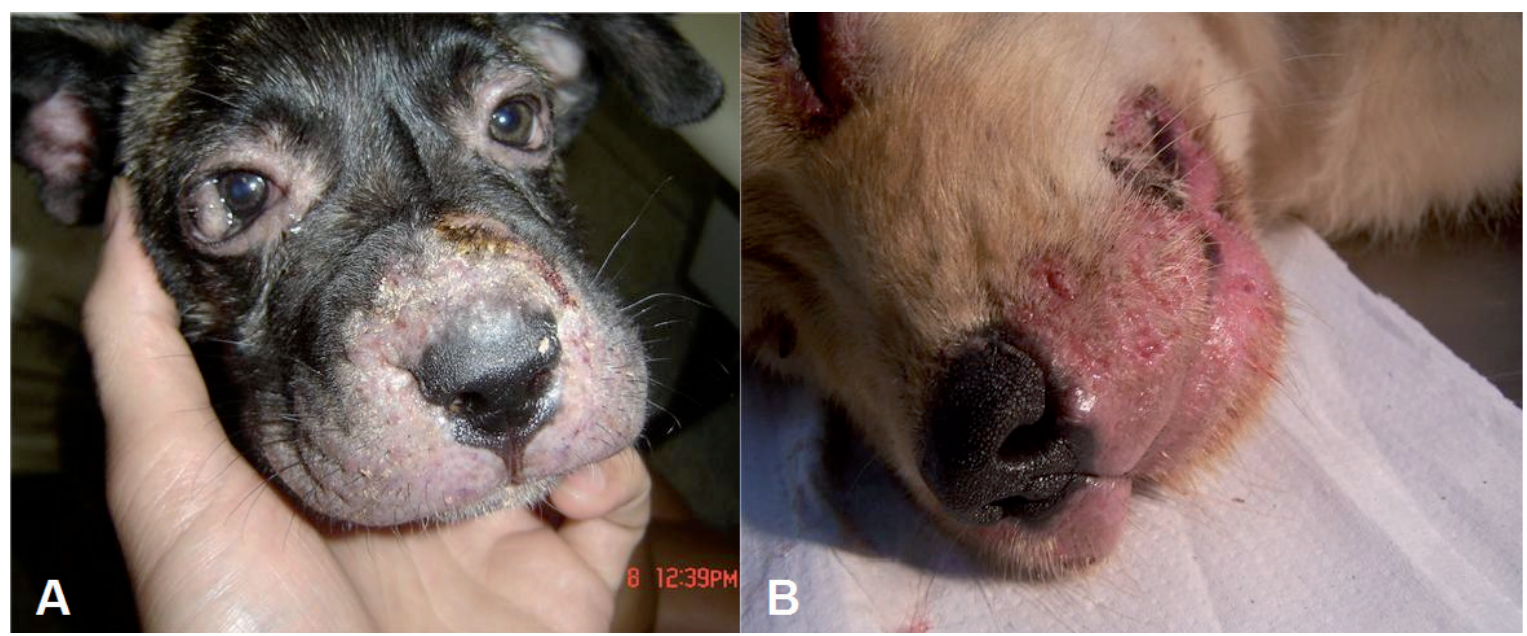

Fonte: Elaboração dos autores. 
O hemograma revelou leucocitose caracterizada por neutrofilia e linfocitose absoluta (2/3). A citologia de material obtido por biópsia aspirativa do linfonodo submandibular revelou grande quantidade de linfócitos sem alterações morfológicas e ausência de bactérias, o que caracterizou um quadro de hiperplasia reativa. A cultura não resultou crescimento bacteriano. Segundo Pasa e Voyvoda (2003), o exame citológico de aspirados de linfonodos afetados, pústulas, abscessos e fluidos raramente revelam bactérias e os resultados da cultura são negativos para o crescimento de bactérias, sugerindo uma etiologia não bacteriana (JEFFERS; DUCLOS; GOLDSHMIDT, 1995).

A avaliação histopatológica (3/3) revelou piogranulomas confluentes, consistindo em aglomerados de macrófagos epitelióides com grupos de neutrófilos em posição central. Além disso, havia acantose multifocal e dilatação de vasos linfáticos superficiais da derme. A avaliação histopatológica de lesões precoces revelaram múltiplos e discretos granulomas e piogranulomas constituídos por grandes aglomerados de macrófagos epitelióides com vários tamanhos de núcleos de neutrófilos, achados esses que foram descritos por Hutchings (2003).

O tratamento utilizado, conforme o descrito na literatura, deve ser precoce e agressivo, caso contrário as cicatrizes podem ser graves (NEUBER et al., 2004). O cão número 1 apresentou poucas cicatrizes, as quais provavelmente ocorreram devido à severidade do quadro e longo período de tratamento até a cura clínica (45 dias). Este animal foi acompanhado por três meses após remissão dos sinais clínicos. O cão número 2 não apresentou cicatrizes e a duração do tratamento foi de 53 dias. $\mathrm{O}$ cão número 3 não apresentou cicatrizes, e ficou sob tratamento durante 60 dias. De acordo com a literatura, é comum ocorrer recidivas (JEFFERS; DUCLOS; GOLDSHMIDT, 1995). Entretanto, isto não foi observado nos animais deste relato.

A celulite juvenil é uma afecção incomum, pouco relatada na literatura, com bom prognóstico quando o diagnóstico precoce é estabelecido e há resposta ao tratamento nos primeiros 5 dias. Na ausência do tratamento, o animal pode vir a óbito. Devese afastar esses animais da reprodução, devido ao caráter genético da doença.

\section{Referências}

CARLOTTI, D. N. Clinical aspects, diagnosis and therapy of canine pyoderma. In: CONGRESS OF THE WORLD SMALL ANIMAL VETERINARY ASSOCIATION, 28., 2003, Bangkok. Proceedings... Bangkok: Blackwell, 2003. p. 20-29.

DAVIDSON, A. P. Juvenile cellulitis. Clinicians Brief, Tulsa, v. 23, n. 4, p. 21-22, 2006.

HUTCHINGS, S. M. Juvenile cellulitis in a puppy. Canadian Veterinary Journal, Ottawa, v. 44, n. 5, p. 418419, 2003.

JEFFERS, J. G.; DUCLOS, D. D.; GOLDSHMIDT, M. H. A dermatosis resembling juvenile cellulitis in an adult dog. Journal of the American Animal Hospital Association, South Bend, v. 31, n. 3, p. 204-8, 1995.

MALIK, R.; DOWDEN, M.; DAVIS, P. E.; ALLAN, G. S.; BARRS, V. R.; CANFIELD, P. J.; LOVE, D. N. Concurrent juvenile cellulitis and metaphyseal osteopathy: an atypical canine distemper virus syndrome. Australian Veterinary Practitioner, St Leonards, v. 25, $\mathrm{n}$. 2, p. 62-67, 1995.

MEDLEAU, L.; HNILICA, K. A. Dermatites imunomediadas. In: MEDLEAU, L.; HNILICA, K. A. Dermatologia de pequenos animais. São Paulo: Roca, 2003, p. 150-151.

NEUBER, A. E.; VAN DEN BROEK, A. H.; BROWNSTEIN, D.; THODAY, K. L.; HILL, P. B. Dermatitis and lymphadenitis resembling juvenile cellulitis in a four-year-old dog. Journal of Small Animal Practice, Gloucester, v. 45, n. 5, p. 254-258, 2004.

PASA, S.; VOYVODA, H. A case of juvenile cellulitis in a dog. The Journal of the faculty of Veterinary Medicine Kafkas University, Turkey, v. 9, n. 2, p. 211-213, 2003.

SCOTT, D. W.; MILLER, W. H. Juvenile cellulitis in dogs: a retrospective study of 18 cases (1976-2005). The Japanese Journal of Veterinary Dermatology, Toquio, v. 13, n. 2, p. 71-79, 2007.

SHIBATA, K.; NAGATA, M. Efficacy of griseofulvin for juvenile cellulitis in dogs. Veterinary Dermatology, Oxford, v. 15, n. 1, p. 20-40, 2004. 